\title{
1968 e a multidão como massa: televisão e imagens políticas da memória e do esquecimento ${ }^{1}$
}

\author{
Marialva Carlos Barbosa
}

Resumo: O artigo analisa imagens produzidas pela televisão acerca do movimento de 1968, no Brasil, usando como material empírico o filme sobre a Passeata dos Cem Mil veiculado pela TV Tupi do Rio de Janeiro, em 26 de junho de 1968. Reflete sobre a construção histórica da ideia de multidão, para em seguida mostrar como a televisão é o lugar de visibilidade para a apresentação da multidão como imagem síntese do século XX.

Palavras-Chave: televisão; multidão; passeata dos Cem Mil.

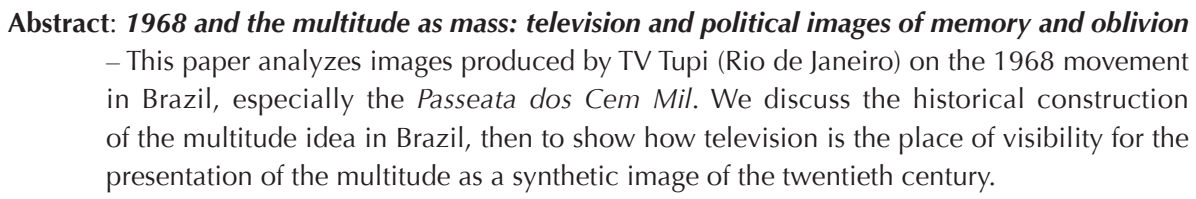

Keywords: televison; multitude; passeata dos Cem Mil.

\section{Introdução}

No século XX, podemos dizer, grosso modo, que os estudos sobre a multidão seguem duas correntes teóricas. Em primeiro lugar, as pesquisas de viés histórico que, influenciadas pela obra clássica de Georges Rudé, A Multidão na História (1991), pensam a multidão como agente em motins, revoltas e rebeliões. E, em segundo, os trabalhos de sociologia, de viés psicológico ou filosófico, que influenciam mais de perto os estudos de comunicação,

1 Texto apresentado no Colóquio Brasil-Argentina. Processos Históricos e Narrativas Audiovisuais. 13 e 14 junho de 2013. Realização ECOPOS/UBA. Apoio CNPq e CONICET. 
produzindo num primeiro momento o público como multidão igualado à massa amorfa e que segue, sem discutir ou refletir, os ditames pautados pelos meios de comunicação.

Assim, de um lado há a tradição da multidão como turba revoltosa, composta pelas "gentes comuns", como enfatiza Thompson (2008), e que, motivada por muitas emoções e não apenas em decorrência da fome (não são "revoltas de barriga", afirma), promove uma série de ações de sublevação contra muitos domínios. Multidão é, então, construída como aglomeração de pessoas que age de maneira violenta e descontrolada contra algo que provoca a revolta. $\mathrm{E}$, de outro, os estudos que refletem sobre a estrutura das massas que se constituem como um novo sujeito social.

A multidão na primeira perspectiva se iguala a grupos populares, ao povo comum, que age e sofre, produzindo, para muitos autores ${ }^{2}$, artefatos de uma cultura que chegam até o presente como restos duradouros. Restos por vezes incompreensíveis em função da distância temporal e das impossibilidades interpretativas construídas pelo olhar estrangeiro que muitas vezes é lançado em direção ao passado. E, na segunda abordagem, a partir da longa linhagem dos estudos sociológicos em torno do então moderno fenômeno do final do século XIX da Psicologia ou das Rebeliões das Massas ${ }^{3}$, a multidão age por impulso, de maneira desordenada, devendo (e podendo) ser controlada a partir de artefatos tecnológicos que ampliam modos de comunicação.

Se no primeiro grupo importa mostrar que a multidão possui um rosto visível e que suas ações podem ser explicadas a partir de uma cultura popular comum, no segundo, é preciso compreender a sua atuação descontrolada e impulsiva para poder controlá-la. Há que se considerar também, nos estudos sobre as multidões, que lentamente se convertem em massas esses agentes que, de personagens sem rosto e sem voz, foram ganhando gradativamente uma identidade visível. A multidão transforma-se no público identificado dos meios de comunicação ${ }^{4}$.

O debate sobre a questão da representação das massas é tema relevante tanto para a história social e cultural, como para os estudos da comunicação, desde os aportes fundadores do campo (Escola de Frankfurt), passando pelas conceituações das diversas correntes norte-americanas do pós-guerra (SCHRAMM, 1970; WRIGHT, 1968, etc.) até os estudos mais recentes que abordam a temática sob a perspectiva do declínio do individualismo (MOSCOVICI, 1985; NEGRI, 2007; MAFFESOLI, 2006). Isso sem esquecer as análises, já referidas anteriormente, que desde o final do século XIX

2 Nessa perspectiva são clássicos os estudos de E. P. Thompson (2008) sobre a economia moral da multidão (A edição original do texto é de 1971) ou a análise de Daniel Roche sobre a cultura popular no século XVIII, nomeada por ele como O Povo de Paris (1998).

3 Estamos nos referindo aos clássicos livros Psicologia das Multidões (1942) de Gustave Le Bon e A Rebelião das Massas (1958) de José Ortega y Gasset. O livro de Ortega y Gasset começou a ser escrito num jornal madrilenho, em 1926. Já a obra de Le Bon, La psycologie de la foule, data de 1895.

4 A longa tradição dos estudos de comunicação caminha da irracionalidade das massas para a apropriação do público como audiência dos meios massivos. Não é o objetivo aqui fazer a análise dessas reflexões. A questão do público como lugar naturalmente massivo produziu a própria adjetivação central da área: os estudos em torno dos processos comunicacionais passaram a ser de comunicação de massa (ou comunicação social). 
(LE BON, 1895; ORTEGAY GASSET, 1926) procuram definir ou valorar esse ator político e cultural fundamental do século XX num mundo que passava por transformações marcantes.

Por outro lado, devemos remarcar a partir de Raymond Williams que a "chave para a compreensão da história cultural nos últimos duzentos anos é a discutida significação da palavra popular" (1997, p. 136) e com ela conceitos extremamente problemáticos como multidão, gente, povo, massa.

É o próprio Williams que, preocupado com a historicidade dos termos, mostra como se passa das multidões referenciadas nos séculos XVI e XVII, quando se reforça a questão da quantificação, para a generalização do termo massas a partir do século XIX: "uma multidão particularmente ingovernável, mais do que uma condição geral. A palavra que passou a ser usada para condição geral foi massa, seguida por massas" (2007, p. 261).

Para Williams, no sentido social moderno, massas e massa têm dois tipos de significados: é a palavra para multidão de muitas cabeças ou turba; e é a descrição das mesmas pessoas vistas como força social positiva ou potencialmente positiva (2007, p. 263). Ou seja, destaca tanto a negatividade quanto a positividade, o que, de certa forma, acompanhou, através do século XX, as apropriações teóricas em torno do conceito.

Ainda que possamos identificar semelhanças no processo de construção do ator político massa na Europa Ocidental e no Brasil, os processos históricos determinam as particularidades da emergência das massas como ator político fundamental no país a partir da década de 1930.

\section{O pensamento conservador e a emergência das massas}

Para diversos teóricos que se ocupam em estudar o pensamento conservador brasileiro (GOMES et al, 1982; VIANNA, 1999; MICELI, 1979; MARTINS, 1979) há, a partir da década de 1920, a produção paulatina e sistemática de ideias em torno do que ficou conhecida também como "modernidade conservadora". Alguns dos principais ideólogos desse pensamento ocupam nos anos seguintes postos chaves no comando político e são responsáveis pela formulação ideológica do Estado (GOMES, 1988).

Francisco Campos (1940a; 1940b), que se tornaria ministro da Justiça durante a ditadura de Getúlio Vargas (1937-1945) e responsável direto pela formulação da ideologia estadonovista, Oliveira Vianna (1982), Alberto Torres (1982) e Azevedo do Amaral (1981) são alguns dos ideólogos que sintetizam as formulações da modernidade conservadora que dominam as ideias políticas no país após $1930^{5}$.

Nessas visões, o Brasil seria obra de uma arquitetura política e a tarefa das elites seria erguer o edifício. Formando o alicerce estariam os hábitos hereditários (elementos da tradição), enquanto os andares dependeriam da orientação geral a ser dada pelos

5 Ângela Castro Gomes (1988) ao estudar o processo de constituição da classe trabalhadora no Brasil identifica nesses ideólogos a edificação de um projeto político que faz da modernização conservadora a doutrina dos anos 1930/1940. 
"homens de estudo e de estado" (TORRES, 1982, p. 23). Eles deveriam organizar o trabalho, formular o corpo homogêneo de ideias e dar direcionamento ao "povo" através de mecanismos educacionais. Seria preciso utilizar as instituições para dar direção geral a quem precisa ser dirigido: o povo. Assim, a educação das elites, a quem caberia a tarefa, ocupa lugar estratégico. Mas há outras concepções presentes na ideia de direcionamento.

A primeira é a constatação de que os homens são por natureza diferentes, havendo aqueles que têm como missão educar e fazer leis a serem cumpridas e todos os outros que devem aprender e obedecer. A desigualdade é, portanto, desejável, já que permitiria, considerando-se as possibilidades e singularidades de cada um, o desenvolvimento diferenciado. Como consequência há a naturalização da hierarquia. A segunda concepção relaciona-se diretamente à ideia nascente de sociedade de massas, em que o indivíduo tem seus comportamentos sociais e morais marcados pela desorientação, sendo a sua característica mais expressiva a existência anônima e uniformizada.

As elites novas e antigas são apresentadas como melhor aparelhadas para desempenhar funções cada vez mais complexas, inclusive a de dar direção ao povo. Por outro lado, apresenta-se como necessidade a difusão de conhecimentos, mesmo que se trate apenas de noções elementares. Nesse ideário, o intelectual e os veículos de difusão - imprensa e literatura - ganham importância decisiva. O que Alberto Torres (1982), por exemplo, entende por educação vai além da tradicional, referente à instrução, envolvendo a orientação dos valores e das representações da sociedade.

Para construir o edifício chamado Brasil propunha-se formular (e estudar) a síntese nacional, para a partir desse conhecimento traçar um programa ideal que atingiria a todos através da educação (diferenciada entre a que deveria ser destinada à massa e aquela que seria própria para os que davam orientações ao "povo") e da massificação das informações. Ao lado disso, instituições fortes baseadas na tradição, nos valores, na disciplina, na autoridade e na hierarquia iriam através de uma política nacional direcionar aquele que recorrentemente era qualificado como "povo brasileiro" (TORRES, 1982; VIANNA, 1982; CAMPOS, 1940a).

Ainda que possamos ver algumas continuidades entre a formulação ideológica dos anos 1920 com a que vigora na virada do século XIX, há entre as duas uma ruptura. O período inicial do experimento republicano deve ser compreendido como radicalmente novo em relação ao anterior, identificado com o atraso colonial ${ }^{6}$. Mas mesmo que houvesse o esforço de particularizar a República com o tempo do progresso, há naquele momento uma pluralidade de propostas políticas. O início da República caracteriza-se pela diversidade de debates e pela luta por um espaço de expressão política (GOMES, 1988).

6 A ideologia do progresso é o ideário da passagem do século XIX para o XX, quando se torna necessário apagar tudo o que lembre o atraso colonial e localizar no futuro o tempo de uma possível redenção. O período foi estudado do ponto de vista de diversas abordagens: as que analisam as transformações urbanas, as que destacam a emergência de discursos civilizatórios, os processos de exclusão dos grupos populares e a formação de discursos disciplinadores, etc. (SEVCENKO, 1985; CHALHOUB, 1986; ENGEL, 1989; NEEDELL, 1993; RAGO, 1987; SCHWARCZ, 1993; SOIHET, 1989; VENTURA, 1991). 
As ideias dos principais ideólogos do conservadorismo brasileiro se articulam como dominantes a partir dos anos 1920, ganhando corpo institucionalizado durante o Estado Novo. Assim, a década de 1930 caracteriza-se como o período áureo da crise das ideologias liberais e da ascensão de valores autoritários, ainda que não se trate de um fenômeno tipicamente brasileiro.

Karl Mannheim (1959) mostra que o conservadorismo, ao perceber a totalidade não mais como soma das partes, passa a conceituar o Estado ou a Nação como algo diverso da soma de seus membros. Os indivíduos são partes de uma totalidade mais ampla. Forma-se uma espécie de "espírito do povo" que domina a ideia de Nação. Por outro lado, os sujeitos isolados são acidentais, em contraste com a unidade territorial indivisível. A Nação é a comunidade com suas gerações passadas, presentes e futuras, materializada a partir da linguagem, costumes e leis comuns, mas também no conjunto de instituições, em antigas famílias e numa família imortal, a do governante. Há no cerne do pensamento conservador moderno a radicalização da individualidade, colocando-se como perspectiva central a naturalização das diferenças. Não há mais espaço para a existência de um indivíduo de caráter universal (MANNHEIM, 1982, p. 129-134).

O apagamento do indivíduo em favor de um povo que constitui o "espírito da Nação" é um dos pilares da ideologia do Estado Novo, que faz do nacionalismo o principal instrumento de sua legitimação. A nova temática passa a fazer parte dos discursos governamentais, como forma de justificar suas realizações, sendo concebida como projeto de governo.

Torna-se imperativo para a consolidação do regime a construção da categoria Nação, e conceitos como nacionalismo e nacional são alvos de disputas de diferentes grupos sociais. O projeto do Estado passa a ser durante a ditadura Vargas a fabricação da mítica da colaboração e da harmonia entre as classes, sendo a questão social sublimada pela ideia de união entre todos os indivíduos, missão do Estado que deve organizar o povo como Nação. Para operacionalizar o projeto, é fundamental apagar o indivíduo, construindo-o como totalidade: o povo, multidão sem rosto e sem identidade própria, as "massas". Nesse cenário, os meios de comunicação (imprensa e o rádio) são vistos como mecanismos indispensáveis para atingir as massas.

No livro O Estado Nacional (1940a), Francisco Campos justifica a criação de um Estado totalitário para substituir o liberal democrático (uma experiência, segundo ele, em processo de decadência) exatamente em função da falência do modelo anterior. O grande perigo, tendo em vista o "crescimento das massas", é a adoção de uma educação liberal. É necessário utilizar todos os esforços no sentido de "conduzir as massas" a um ideário comum (CAMPOS, 1940a, p. 63).

Vive-se um "estado de massas", sendo necessária uma nova e complexa estruturação. Os mecanismos utilizados pelo liberalismo não mais se adaptam aos novos tempos. No mundo moderno predomina a "cultura de massa" - é no texto de Campos que a expressão aparece 
como ideologia política pela primeira vez -, o que acaba gerando a mentalidade de massa, uma nova forma de integração que se origina nos mecanismos de contágio através da ação difusora dos meios de comunicação (1940a, p. 63) ${ }^{7}$. No texto também está presente a ideia de irracionalidade das multidões e o seu domínio só é possível através da construção de mitos.

As massas devem, então, ser unificadas em torno de um mito que corporifica a figura do chefe. No caso do Estado Novo esse mito é construído em torno de Getúlio Vargas, o "pai dos pobres" e chefe supremo da Nação. A racionalização do comportamento das massas se dá através do destaque ao líder carismático, centro da integração política e sustentáculo do totalitarismo (CAMPOS, 1940a, p. 30-31).

O regime político ideal para as massas, para Campos, só pode ser a ditadura. "No estado totalitário desaparecem as formas atuais do conflito político" (1940a, p. 31). O novo Estado se caracteriza pelo clima de ordem garantido por um chefe que encarna o espírito de comunhão com o povo, do qual é guia e, ao mesmo tempo, condutor. Só ele pode tomar decisões, encarnando a vontade e os anseios das massas. O chefe e o povo formam, num processo simbiótico, o novo Estado e seu caráter popular.

Produto direto do pensamento conservador brasileiro, do ponto de vista ideológico, e das mudanças políticas e econômicas que transformaram o país durante o Estado Novo $(1930-1945)^{8}$, a identificação dos grupos populares como massa faz parte do projeto político conservador desde os anos 1920. Portanto, podemos dizer que a ideia de povo - massa amorfa indiferenciada - e que, em função disso, deveria ser guiado e conduzido é construída no interior do pensamento conservador brasileiro.

Há que se considerar ainda o fato de a multidão, a turba, ser frequentemente identificada às revoltas levadas a cabo nos séculos XVIII e XIX e o medo que causava, então, a eminência das multidões de escravos de se rebelarem contra o sistema servil. As proibições contra ajuntamento e aglomerações de negros nos espaços públicos, frequentemente referidas durante o século XIX, deixam antever o medo das "cidades negras", como o Rio de Janeiro, diante da possível ação desses grupos. A multidão era temida e contra a sua formação não se media esforços ${ }^{9}$.

A emergência da República, por outro lado, significa o apagamento da multidão. Referências à maneira apática como a população assiste as ações da Proclamação

7 Observa-se no pensamento de Francisco Campos indícios das formulações de Gustave Le Bon (edição original de 1895). Tendo como inspiração a multidão de proletários das cidades europeias no final do século XIX. Para Le Bon a massa irracional deveria ser compreendida e controlada. A civilização industrial não seria possível sem as multidões e o modo de sua existência era a turbulência. O futuro seria daqueles que compreendessem as formas de manipular a psicologia das multidões, seduzindo-as com imagens impressionantes.

8 Estado Novo considerado como o período de 1930 a 1945 em que houve um conjunto de mudanças e que passaria à história como "Era Vargas": o Governo Provisório (1930-1934), o Governo Constitucional (1934-1937) e o Período Ditatorial (1937-1945). Esses três momentos representam o desdobramento do processo político que se inicia com a ascensão ao poder da Aliança Liberal.

9 O termo é utilizado por Chalhoub (1990). O medo ainda existe no início do século XX, quando medidas saneadoras da capital da República tinham como foco a expulsão dos grupos populares dos espaços centrais da cidade. Sobre o tema, cf. CHALHOUB, (1986); SEVCENKO, (1985); RAGO, (1987), dentre outros. 
da República, lembradas pelos contemporâneos ou por estudiosos do século $\mathrm{XX}^{10}{ }^{10}$, indicam o movimento de dissolução das multidões.

Assim, ainda hoje levamos sustos quando diante de fotografias descobrimos a multidão que segue cortejos fúnebres de personagens então populares, como Machado de Assis, João do Rio ou o Barão do Rio Branco. As imagens publicadas pelo jornal A Noite, em 10 de fevereiro de 1912, mostram a multidão acompanhando o enterro do Barão do Rio Branco com ar contido, assim como impressiona a compacta multidão que segue o cortejo de João do Rio por toda a Avenida Rio Branco: segundo os jornais da época, 100 mil pessoas pararam o centro do Rio para acompanhar o féretro do escritor (O Paiz, 24/06/1921, p. 3). Gradualmente vai se tornando emergente domesticar a multidão transformando-a em massa.

Inspirado no autoritarismo europeu, o pensamento conservador brasileiro ganhou, portanto, nuanças particulares. Numa sociedade que não reconhece o indivíduo como parte de uma totalidade, mas que a constrói como uma família imortal personificada na imagem mítica do governante, é necessário fazer ecoar a sua voz mitológica através de um meio no qual é impossível visualizar o rosto do público. A voz audível do rádio produz nos anos 1930/1940 um ouvinte igualado à condição de público-massa. E quando a televisão irrompe a cena, já nos anos 1950, encontra como auditório potencial a ser conquistado o mesmo ator coletivo.

\section{Televisão e multidão}

A chave para a compreensão dos processos comunicacionais no Brasil a partir de 1960 é a percepção de que os meios se dirigem cada vez mais a uma multiplicidade de rostos, qualificado e percebido como povo, massa, multidão. Há a busca pela expansão do auditório e a presunção de que a eficácia da comunicação se faz pela aproximação de um leitor/espectador/ouvinte, mas que assume o lugar de público em contato com as indústrias midiáticas que se consolidam.

A década de 1960 abre o calendário de um tempo em que o povo, a massa, se transforma no público almejado pelos velhos e pelos novos meios de comunicação. Ainda que o rádio fosse o meio por excelência dos grupos populares, a televisão inicia um longo caminho no sentido de construir uma linguagem que a aproxime do seu público, moldado paulatinamente nas décadas seguintes (BARBOSA, 2013).

Alexandre Bergamo (2010) identifica o período inicial da televisão como aquele em que o público é caracterizado como a família, mas num processo que tem início na década de 1960 passa a ser dirigida a um "público" e a um "povo" cuja imagem é essencialmente moral. Além disso, a ficção da sua dramaturgia se afasta do teatro consagrado e se aproxima de duas categorias essenciais que definem o modo de fazer TV: "povo" e "realidade" (BERGAMO, 2010, p. 61-71).

10 Ver a este respeito CARVALHO, J. M. (1987). 
No final da década, o público definitivamente se transforma em índices de audiência, num momento em que o valor comercial do meio começa a ser inquestionável, passando a ser determinado pela quantidade dos que estão diante dos aparelhos.

Se inicialmente é preciso veicular discursos que unam os valores dos grupos dominantes com os da classe média em franca expansão, posteriormente será preciso incluir a massa amorfa, sem voz e sem rosto, que, diante dos meios, via a vida política e cotidiana se desenrolar em capítulos nem sempre compreensíveis.

A revolução popular antevista no período pré-1964 causa pânico e medo e une as forças conservadoras do país em torno de um discurso comum, veiculado pelos meios de comunicação: opunha-se deliberadamente democracia e comunismo. O temor se apodera dos grupos dominantes frente à expressão de vozes populares. É preciso alargar o auditório da propaganda anticomunista e, mais uma vez, os meios de comunicação são fundamentais.

Cada época histórica está encharcada de modos de ver: há regimes de visualidade próprios, da mesma forma que a imagem é percebida ao longo da história de maneiras específicas. Nesse sentido, a televisão é um meio que exacerba o mundo visual, em função de múltiplos processos, nos quais a eclosão de aparelhos tecnológicos que se antepõem ao olho humano constrói uma réplica do visível.

Trata-se de um meio de comunicação concebido como parte de um crescimento permanente (de audiência, de expansão territorial, de difusão das fronteiras do nacional, de consumo, de quantidade de horas de transmissão, de oferta de canais, etc.). Essas características exigem que a televisão faça do novo e do imediato seu valor mais expressivo e a consolidação do seu discurso depende de esquemas facilmente reconhecíveis para as suas audiências e que geram hábitos de recepção.

A televisão constrói modos de ver repetitivos e esquemáticos, mas essa repetição e a continuidade da vida cotidiana na tela de TV não são compatíveis com a ideia de novidade, fundamental na construção da sua narrativa. Daí a necessidade permanente de acontecimentos extraordinários. O novo, o imediato colocado em cena, graças à técnica do ao vivo, junto com as imagens extraordinárias do mundo constroem a marca narrativa, pelo menos do ponto de vista do discurso informacional, da televisão (VARELA, 2007, p. 21).

O "século das massas", no qual a imagem ocupa lugar central, significa também a proliferação do visível e a sua inscrição em outros registros de visibilidade (ARFUCH; DEVALLE, 2009), e a televisão torna-se relevante para mostrar como esse substantivo fluido e indefinido (povo, massa, multidão) aparece ali representado (TRATNER, 2008). Portanto, podemos dizer que há uma história política que se representa nas imagens de massa que os meios de comunicação, em função das possibilidades tecnológicas de cada época, colocam em cena.

Desde o final do século XIX a multidão esteve presente com recorrência nos meios visuais modernos (fotografia, cinema, etc.), estando sua emergência relacionada 
à sua visibilidade nas grandes cidades (MOSCOVICI, 1985; ORTIZ, 1996) e ao próprio conceito de massa. A televisão deve ser vista como o meio de comunicação, inclusive do ponto de vista narrativo, destinado a este público massa. É onde a multidão se apresenta como síntese da imagem do século XX.

\section{Televisão e imagens de 1968}

Poucos foram os registros que atravessaram as décadas e que mostram, hoje, em preto e branco, cenas veiculadas na televisão sobre as manifestações contra a ditadura militar em 1968. Muitas delas se transformaram em imagens símbolos de uma época e do movimento político das esquerdas contra o Golpe de 1964.

Algumas dessas imagens foram produzidas durante o que ficou conhecido como a Passeata dos Cem Mil, que reuniu no centro do Rio, em 26 de junho de 1968, 100 mil pessoas para protestar contra os atos de truculência e repressão da polícia que acabaram por assassinar o secundarista Edson Luís, no restaurante do Cabalouço. Organizada pela União Nacional dos Estudantes (UNE), a manifestação tinha como propósito protestar contra a morte do jovem, mas objetivava também oferecer um espetáculo público de repúdio à ditadura.

O escritor Ferreira Gullar define o contexto da época:

1968 foi ano da virada pra pior. O regime militar, com três anos de vida, desgastara-se aos olhos da classe média que apoiara o golpe. A morte do estudante Edson Luís, em março, possibilitou a mobilização da opinião pública contra a ditadura (Passeata dos Cem Mil), mas ao mesmo tempo fortaleceu a extrema direita militar que, em dezembro, impôs a edição do Al-5 e efetuou centenas de prisões (GULLAR, 1988, p. 15).

A morte do estudante foi o estopim para as grandes manifestações, das passeatas mostradas em cenas que se repetiam nos jornais da noite na televisão, algumas delas que se tornaram imagens símbolos e outras que se construíram como imagens do esquecimento.

A multidão é congelada em torno da imagem de Tiradentes, em frente ao atual prédio da Assembleia Legislativa no centro do Rio de Janeiro, e do líder estudantil Valdemir Palmeira que discursa enquanto gesticula vigorosamente. Reproduzida nos jornais diários e colocada em movimento pela televisão, se torna uma imagem política transmitida pela TV e fixada pelos periódicos.

No filme de 36 segundos, que recupera a passeata, algumas tomadas gerais de várias ruas são mostradas, passando rapidamente de uma rua a outra, apresentando sempre a multidão. Avenida Rio Branco, Avenida Presidente Vargas, com a igreja da Candelária ao fundo e, finalmente, Rua Primeiro de Março são os lugares de memória do movimento político. A profusão de lugares indica também as estratégias de edição do filme. É como se a multidão se multiplicasse e como se ela caminhasse e as câmaras acompanhassem detidamente cada movimento. 
O filme começa com a Cinelândia apinhada de gente. Do alto, a câmara filma a praça tomada pela multidão. Ao fundo o Teatro Municipal, e a câmara desliza do alto indo em direção ao ponto onde está a maior aglomeração. As faixas ao longe tornam os dizeres imperceptíveis. O que importa é a multidão que se move, se aglomera, anda, se dispersa e se concentra num movimento incessante. As imagens compostas para serem encenadas para o público indicam uma multidão se constituindo pela ação.

Um corte abrupto e a multidão está nas esquinas da Avenida Rio Branco com Presidente Vargas. A câmara do alto, como um olho vigilante, acompanha o cortejo principal, com militantes segurando faixas que expressam palavras de ordem e o público que olha o desfile condenatório ao regime militar.

Mais um corte e aparecem alguns personagens em primeiro plano, num outro cenário: a Avenida Presidente Vargas, com a Candelária ao fundo. Algumas pessoas olham a ermo, mas a câmara desliza novamente para a multidão, agora concentrada nas escadarias do Palácio Tiradentes. O cortejo atinge o clímax: o local do comício, onde palavras de ordem ecoam na memória de quem descreve, mas não são audíveis no filme que, sem qualquer sonoridade, traz o passado para o presente.

A última imagem apresenta uma cena que congelada indica milhares de rostos e corpos imperceptíveis individualmente. A multidão está encenada pela lógica narrativa da imagem em movimento: pedaços de gente que se aglomeram em um lugar indiferenciado produzindo a sensação de humanidade amorfa.

As imagens de grupos em bloco, sem rostos definidos, molda a perspectiva política dominante daqueles episódios de junho de 1968 que foram elevados à condição de imagem símbolo das forças contrárias ao regime. Em poucos momentos aparecem rostos perfeitamente identificáveis e mesmo os líderes do movimento não são registrados em close.

Por outro lado, há um conjunto de imagens que não apareceram nem nas emissões, nem nas memórias duradouras de 1968. Esse grupo de fotografias sequer tem autoria. Todas foram doadas por personagens anônimos ao acervo do Arquivo Geral da Cidade do Rio de Janeiro e lá continuam até hoje.

Vinte anos depois, ao publicar algumas delas num livro denominado Um Rio em 68, postam ali algumas dessas fotografias que podem ser qualificadas como imagens do esquecimento. Não por acaso se distribuem ao final do livro, nas suas últimas páginas.

Para elas podemos dar um título que resume o pressuposto central do esquecimento: as imagens que não vimos. E são algumas delas que fecham esse texto que procurou refletir sobre as pertinências e as permanências das imagens produzidas, fixadas (ou esquecidas) pela televisão (e pelos meios de comunicação). 


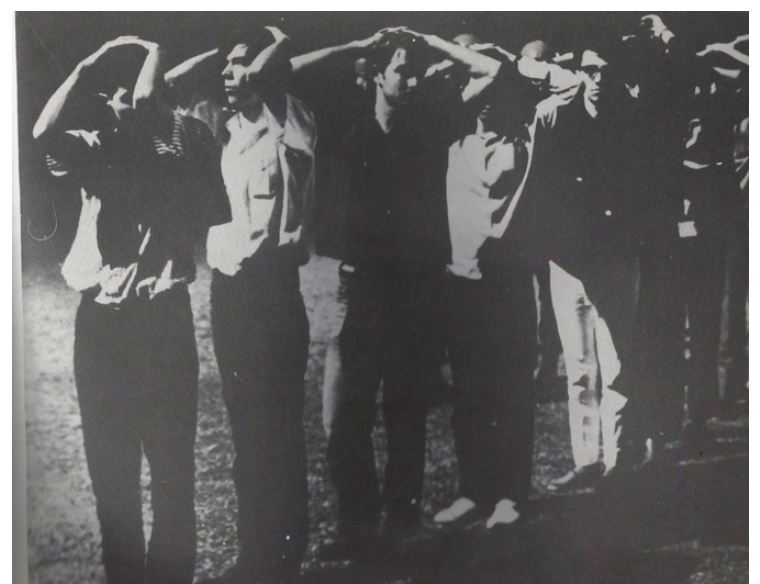

Fig. 1. Prisioneiros de 1968. Fonte: Um Rio em 68. Secretaria Municipal de Cultura/Biblioteca Carioca, 1988.

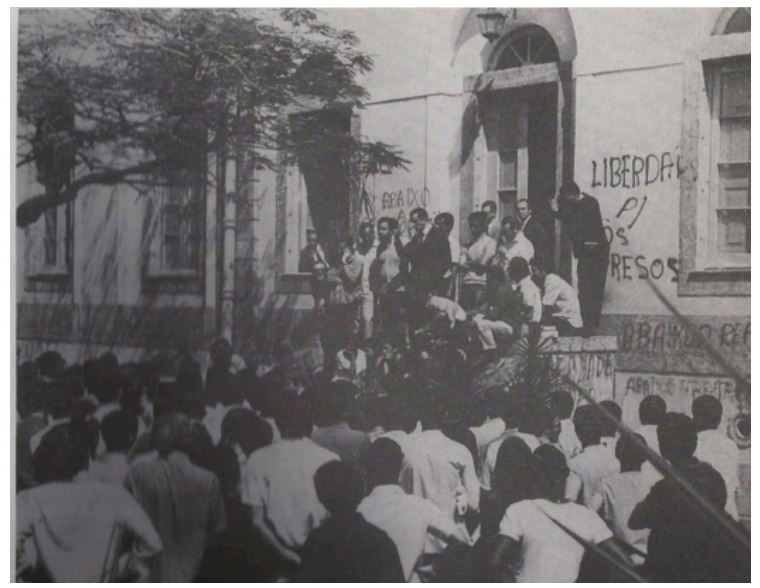

Fig. 2. Protestos de estudantes nas escadarias (da hoje Escola de Comunicação) UFRJ. Fonte: Um Rio em 68. Secretaria Municipal de Cultura/Biblioteca Carioca, 1988.

Marialva Carlos Barbosa é professora titular da Escola de Comunicação da Universidade Federal do Rio de Janeiro (UFRJ). Professora do Programa de Pós-Graduação de Comunicação e Cultura da UFRJ, vice-presidente da INTERCOM e pesquisadora 1D do CNPq.

marialva153@gmail.com 


\section{Referências}

AMARAL, A. O Estado autoritário e a realidade nacional. Brasília: UNB, 1981.

ARFUCH, L.; DEVALLE, V. (orgs). Visualidades sin fin. Imagen y diseño en la sociedad global. Buenos Aires: Prometeo, 2009.

BARBOSA, M. História Cultural da Imprensa (1900-2000). Rio de Janeiro: MauadX, 2007.

História da Comunicação no Brasil. Petrópolis: Vozes, 2013.

BERGAMO, A. A reconfiguração do público. In: RIBEIRO, A. P. G.; SACRAMENTO, I.; ROXO, M. (orgs.). História da televisão no Brasil: do início aos dias de hoje. São Paulo: Contexto, 2010.

CAMPOS, F. O Estado Nacional. Sua estrutura, seu conteúdo ideológico. Rio de Janeiro: José Olympio, 1940a.

. Educação e cultura. Rio de Janeiro: José Olympio, $1940 \mathrm{~b}$.

CARVALHO, J. M. de. Os bestializados: o Rio de Janeiro e a República que não foi. São Paulo, Companhia das Letras, 1987.

CHALHOUB, S. Trabalho, lar e botequim. O cotidiano dos trabalhadores no Rio de Janeiro da belle époque. São Paulo: Brasiliense, 1986.

. Visões da liberdade. Uma história das últimas décadas da escravidão na Corte. São Paulo: Companhia das Letras, 1990.

ENGEL, M. Meretrizes e doutores. Saber médico e prostituição no Rio de Janeiro (1840-1890). São Paulo: Brasiliense, 1989.

GOMES, A. de C. et al. Estado Novo. Ideologia e Poder. Rio de Janeiro: Zahar Ed., 1982.

A invenção do trabalhismo. Rio de Janeiro, IUPERJ, 1988.

GULLAR, F. Depoimento. In: Um Rio em 68. Rio de Janeiro: Secretaria Municipal de Cultura, 1988.

LE BON, G. Psicología de las multitudes. Buenos Aires: Editorial Albatros, 1942.

MAFFESOLI, M. O tempo das tribos. 4 ed. Rio de Janeiro: Forense Universitária, 2006.

MANNHEIM, K. Essays on sociology and social psychology. Londres: Routledge and Kegan Paul Ltda, 1959.

. O significado do conservadorismo. In: FORACCHI, M. M. (org). Sociologia - Mannheim. São Paulo: Ática, 1982.

. O pensamento conservador. In: MARTINS, J. de S. (org.). Introdução crítica a sociologia rural. São Paulo: HUCITEC, 1986.

MARTINS, W. História da inteligência brasileira. v. 7: 1930-1960. São Paulo: Cultrix, 1979

MICELI, S. Intelectuais e classe dirigente no Brasil: 1920-1945. São Paulo: DIFEL, 1979.

MOSCOVICI, S. La era de las multitudes. Un tratado histórico de psicología de las masas. FCE, 1985.

NEEDELL, J. D. Belle époque tropical: sociedade e cultura de elite no Rio de Janeiro na virada do século. São Paulo: Cia das Letras, 1993.

NEGRI, A. Multidão. Rio de Janeiro: Record, 2007.

ORTEGA Y GASSET, J. A rebelião das massas. Rio de Janeiro: Livro Ibero - Americano, 1958. 
ORTIZ, R. Cultura, comunicación y massa. Otro territorio. Ensayos sobre el mundo contemporáneo. UNQUI, p. 93-125, 1996.

PREFEITURA DO RIO DE JANEIRO. Secretaria Municipal de Cultura/Biblioteca Carioca. Um Rio em 68. Rio de Janeiro: Secretaria Municipal de Cultura, 1988.

RAGO, M. Do cabaré ao lar. A utopia da cidade disciplinar. Brasil 1890-1930. Rio de Janeiro: Paz e Terra, 1987.

ROCHE, D. Povo de Paris. Ensaio sobre a cultura popular no século XVIII. São Paulo: Edusp, 1998.

RUDÉ, G. A multidão na história: estudos dos movimentos populares na França e na Inglaterra 17301848. Rio de Janeiro: Campus, 1991.

SCHRAMM, W. Comunicação de massa e desenvolvimento. Rio de Janeiro: Bloch Editores, 1970.

SCHWARCZ, L. M. O espetáculo das raças: cientistas, instituições e questão racial no Brasil - 18701930. São Paulo: Cia das Letras, 1993.

SEVCENKO, N. Literatura como missão (tensões sociais e criação cultural na Primeira República). São Paulo: Brasiliense, 1985.

SOIHET, R. Condição feminina e formas de violência: mulheres pobres e ordem urbana - 1890-1920. Rio de Janeiro: Forense Universitária, 1989.

THOMPSON, E. P. A economia moral da multidão na Inglaterra do século XVIII. Lisboa: Antígona, 2008.

TORRES, A. O problema nacional brasileiro. Brasília: UNB, 1982.

TRATNER, M. Crowds Scenes. Movies and Mass Politics, Nova York: Fordham University Press, 2008.

VARELA, M. Las imágenes del 68 en la historia de la cultura audiovisual. Contracampo, Revista do PPGCOM-UFF, 2 sem., p 19-42, 2007.

VENTURA, R. Estilo tropical: história cultural e polémicas literárias no Brasil, 1914. São Paulo: Cia das Letras, 1991.

VIANNA, L. J. W. Liberalismo e sindicato no Brasil. Belo Horizonte: UFMG, 1999.

VIANNA, O. Populações meridionais do Brasil. Brasília: UNB, 1982.

Evolução do povo brasileiro. Rio de Janeiro: José Olympio, 1956.

WILLIAMS, R. Cine y socialismo. In: (org.). La política del modernismo. Buenos Aires: Manantial, 1997.

. Marxismo e literatura. Rio de Janeiro: Zahar Ed., 1979.

WILLIAMS, R. Massas. In: Palavras-chave: um vocabulário de cultura e sociedade. São Paulo: Boitempo, 2007.

WRIGHT, C. Comunicação de massa. Rio de Janeiro: Bloch Ed., 1968. 